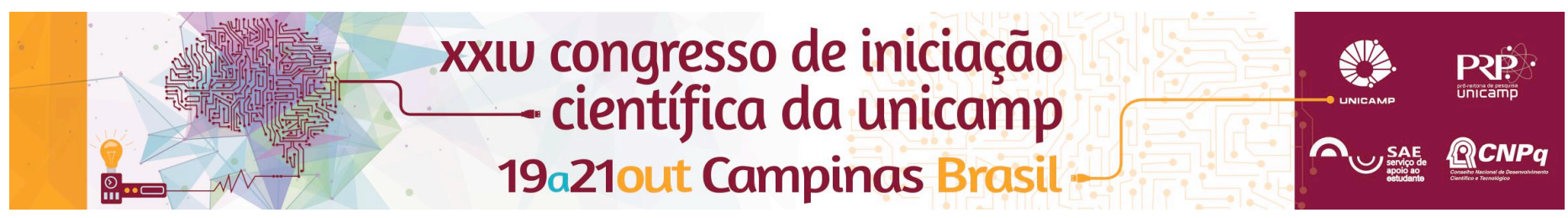

\title{
Formulation of an eco-friendly agrochemical spray containing silver nanoparticles against citrus canker
}

\section{Bruna F. Morais*, Caio H. N. Barros, Danijela Stanisic, Ljubica Tasic}

\section{Abstract}

In this work, we present a method for producing biogenic silver nanoparticles (AgNP) using citrus waste and studies on the production of a green pesticide against the bacteria responsible for citrus canker in orange plantations.

\section{Key words: Silver nanoparticles, pesticide, Xanthomonas axonopodis pathovar citri.}

\section{Introduction}

Silver nanoparticles (AgNPs) are small aggregates of elemental silver that exhibit several interesting biological effects. In recent years, many biological, green and nontoxic synthetic routes have been proposed using plant extracts as a source of reducing and stabilizing agents for AgNPs production ${ }^{1}$. These nanoparticles often present antimicrobial activity, which makes them remarkably valuable in several research fields. Bearing in mind the vast damages caused by the bacteria Xanthomonas axonopodis pv. citri (Xac) in orange plantations in Brazil ${ }^{2}$, the development of an agrochemical containing this nanomaterial would be of great importance in the Brazilian agriculture. In order to accomplish this goal, the formulation of a product with appropriated adjuvants that aid in foliar uptake, make more viable spread and delivery of the nanomaterial is essential. Nowadays, biodegradable, non-toxic surfactants and wetting agents have been extensively pursued to facilitate the crossing of the acitve ingredient through the epicuticular wax and cuticle of the leaf ${ }^{3}$. Here, we present a method for production of AgNPs using water extracts from orange (Citrus sinensis) peel and the first studies on the formulation of an eco-friendly agrochemical that contains adjuvants with low toxicity. This spray is going to be tested in vivo in orange plantations against the citrus canker caused by $X a c$, and our expectations are that in vitro activity against $X a c$ are going to be confirmed.

\section{Results and Discussion}

The biogenic synthesis of AgNPs from citrus waste was carried out by collecting Citrus sinensis peel after juice extraction, followed by washing and cutting it into $\sim 0,5$ $\mathrm{cm}^{2}$ pieces. The peel was stirred in water until the boiling point. After simple filtration, vacuum filtration using 0.22 $\mu \mathrm{m}$ pore filter was performed. A $1 \mathrm{mmol} \mathrm{L}^{-1} \mathrm{AgNO}_{3}$ solution was added to the orange peel extract, triggering the formation of the nanoparticles (Image 1).
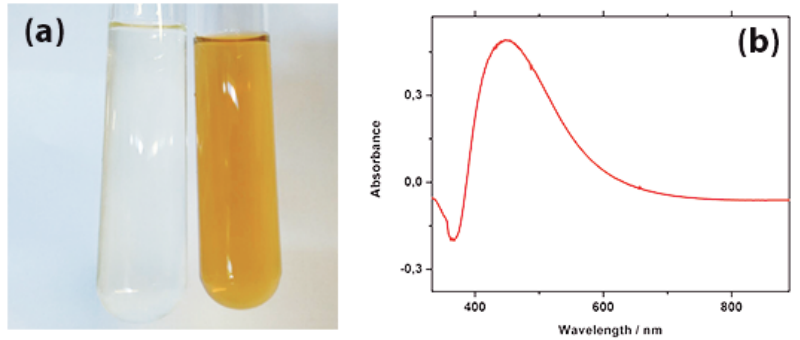

Image 1. (a) Solution of orange peel extract (left) and the corresponding suspension of silver nanoparticles; (b) Plasmon resonance band of formed AgNPs at $446 \mathrm{~nm}$.
In order to improve foliar uptake of AgNPs, after completion of their synthesis, adjuvants were added. Surfactants diminish the surface tension of the solution, thus, increase contact area with the leaf. In contrast, thickening agents and polymers increase the viscosity, avoiding droplet drift (Image 2).
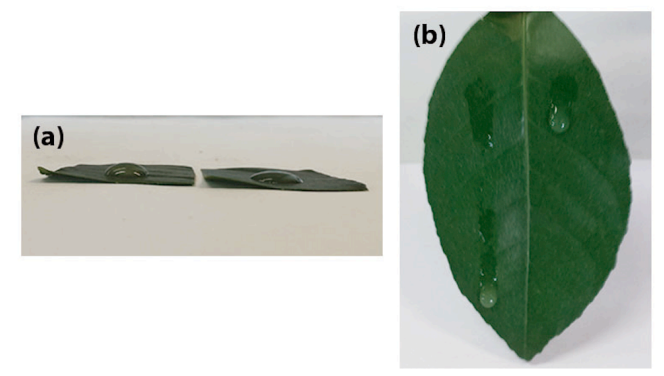

Image 2. Effect of adjuvants on Citrus leaves; (a) showing decrease of the contact area by addition of Pluronic F127 (right) and (b) the increase of viscosity by the addition of glycerol (right).

As to provide adequate physico-chemical properties to the formulation, added adjuvants must not drastically change the AgNPs polydispersity and size. Measurements of size by Dynamic Light Scattering were performed to evaluate these changes (Chart 1).

Chart 1. Influence of some adjuvants on AgNPs size:

\begin{tabular}{lll}
\hline \multicolumn{1}{c}{ Adjuvant } & \multicolumn{1}{c}{ Type } & Size / nm \\
\hline None & - & $290 \pm 15$ \\
\hline $\begin{array}{l}\text { Ethoxylated Sorbitan } \\
\text { Monolaurate 80 EO 0.01\% }\end{array}$ & $\begin{array}{l}\text { Non-ionic } \\
\text { surfactant }\end{array}$ & $270 \pm 10$ \\
\hline Pluronic F127 0.05\% & $\begin{array}{l}\text { Non-ionic } \\
\text { surfactant }\end{array}$ & $290 \pm 10$ \\
\hline Pectin 0.01\% & Polysaccharide & $260 \pm 10$ \\
\hline
\end{tabular}

\section{Conclusions}

Silver nanoparticles were produced using citrus waste in a green way. Already conducted studies indicate the feasibility of a formulation of a spray that contains AgNPs, leading to good perspectives towards an agrochemical that can be used in the citriculture against $X a c$.

\footnotetext{
Ahmed, S.; Ahmad, M.; Swami, B. L. and Ikram, S. J. Adv. Res. 2016, 7, 1728.

Sanches, A. L. R.; Miranda, S. H. G.; Junior, J.B.; Bassanezzi, R. B. Rev. Enon. Sociol. Rural. 2014, 52, 549-566.

3 Castro, M. J. L. And Ojeda, C. Environ. Chem. Lett. 2014, 12, 85-95.
} 